\title{
SISTEM PENGHARGAAN SEBAGAI VARIABEL MODERATING DALAM HUBUNGAN ANTARA GAYA KEPEMIMPINAN DAN KINERJA MANAJERIAL (STUDI PADA SUPERMARKET DI KOTA MATARAM)
}

\section{SRI AYU FEBRIANTI ${ }^{11}$, I GUSTI AYU OKA NETRAWATI ${ }^{2)}$, I GUSTI PUTU BAGUS SUASTINA ${ }^{3)}$,}

\author{
Dosen STIE 45 Mataram \\ ${ }^{1)}$ aditzfa85@gmail.com, ${ }^{2)}$ igaokanetrawati2017@gmail.com, ${ }^{3)}$ suastina1957@gmail.com
}

\begin{abstract}
ABSTRAK
Penelitian ini bertujuan untuk menganalisis pengaruh gaya kepemimpinan terhadap kinerja manajerial dan pengaruh gaya kepemimpinan terhadap kinerja manajerial dengan dimoderasi oleh variabel sistem penghargaan. Jenis penelitian adalah assosiatif. Responden adalah manajer dan staf dengan level terendah supervisor di seluruh supermarket di Mataram, sebanyak 66 responden. Teknik penyampelan sensus. Analisis data dilakukan dengan regresi sederhana dan Moderated Regression Analysis (MRA).

Hasil penelitian menunjukkan bahwa gaya kepemimpinan berpengaruh signifikan terhadap kinerja manajerial, namun arah hubungannya negatif dan sistem penghargaan berpengaruh negatif pada hubungan gaya kepemimpinan terhadap kinerja manajerial.
\end{abstract}

Kata Kunci : Hubungan, kepemimpinan, kinerja manajerial, sistem penghargaan.

\section{ABSTRACT}

The aim of this study is to analyzed the influence of leadership style on managerial performance and the reward system as the moderating variable that may affect the relationship of leadership style on managerial performance. The type of this research is associative. Respondents are managers and staff with the lowest level of supervisor in the entire supermarket in Mataram, as many as 66 respondents. Sampling technique is census. Using simple regression analysis and Moderated Regression Analysis (MRA) as analysis.

The results showed that leadership style negative significantly influence on managerial performance and the reward system influence negatively significant the relationship of leadership style on managerial performance.

\section{Keywords : $\quad$ relationship, leadership, managerial performance, reward system.}

\section{PENDAHULUAN}

Persaingan perusahaan di pasar global menyebabkan persaingan yang ketat antar perusahaan. Oleh karena itu, perusahaan harus mengelola bisnis secara efektif dan efisien melalui peningkatan kinerja disamping peningkatan kualitas produk dan jasa. Kebutuhan manusia yang semakin meningkat dan banyak memungkinkan perkembangan bisnis ritel yang pesat. Apabila suatu perusahaan ritel sudah bisa mendapatkan konsumen, langkah selanjutnya adalah bagaimana agar konsumen tersebut bisa menjadi pelanggan tetapnya dan mempertahankan loyalitas konsumen untuk terus bisa berbelanja di perusahaan ritel tersebut.

Supermarket adalah salah satu bentuk retailing semacam perusahaan atau industri yang dapat meningkatkan nilai produk dan jasa yang dijual kepada konsumen dan memudahkan distribusi produkproduk tersebut bagi perusahaan yang memproduksinya. Keberadaan beberapa supermarket saat ini sangat membantu masyarakat, disamping harganya yang bersaing, juga waktu buka yang lebih cepat, sehingga masyarakat yang memiliki waktu yang terbatas dapat berbelanja. Persaingan dalam bisnis supermarket menjadi semakin kompetitif, sehingga pihak manajemen dalam perusahaan dituntut untuk selalu mempelajari teknik baru yang digunakan untuk memotivasi pegawai agar dapat meningkatkan pelaksanaan kinerja dan 
menciptakan lingkungan yang harmonis serta memaksimalkan efektivitas setiap individu. Perlu juga adanya pendekatan kontingensi. Keyakinan dasar dari pendekatan kontingensi ini adalah perilaku pemimpin yang efektif pada situasi tertentu belum tentu efektif dalam situasi lainnya. Artinya, keefektifan seorang pemimpin tergantung (kontingen) pada situasi organisasi dan bukan sebaliknya bahwa perilaku yang efektif pada satu situasi akan efektif juga pada situasi lainnya (Safaria, 2004:65). Selain pendekatan kontingesnsi, juga perlu adanya perhatian terhadap kinerja manajerial.

Kinerja manajerial memperlihatkan gambaran mengenai tingkat pencapaian seorang individu dalam melaksanakan fungsi-fungsi manajemen (Nurfitriana et al., 2005). Manajer membuat keputusan, mengalokasikan sumber daya, dan mengatur aktivitas anak buahnya untuk mencapai tujuan. Manajer terlibat dalam keempat aktivitas manajerial diantaranya adalah manajemen tradisional, komunikasi, manajemen sumber daya manusia, dan pembangunan jaringan (Robbins et al., 2009:9). Sedangkan Manajemen yang efektif juga mengharuskan seorang pemimpin untuk menemukan cara terbaik dalam mempekerjakan para bawahannya agar dapat mencapai tujuan perusahaan. Seorang pemimpin perlu melakukan upaya untuk mempengaruhi tingkah laku bawahannya, baik dengan pendekatan secara pribadi maupun dengan menggunakan gaya kepemimpinan yang konsisten agar kebutuhan dan kepentingan setiap karyawan dapat diketahui. Gaya kepemimpinan (leadership styles) adalah berbagai pola tingkah laku yang disukai oleh pemimpin dalam proses mengarahkan dan mempengaruhi bawahan (Sumarno, 2005).

Pokok teori Fiedler ini berfokus pada apakah seorang pemimpin menekankan pada gaya orientasihubungan (relationship-oriented) atau gaya orientasi-tugas (task-oriented) (Safaria, 2004:66). Pada gaya orientasi-hubungan, pemimpin menekankan pada terciptanya kepercayaan dan penghormatan timbal balik, mendengarkan kebutuhan bawahan dan komunikasi dua arah. Pada gaya orientasi-tugas, pemimpin lebih menekankan pada penyelesaian tugas dan pencapaian prestasi tertinggi dari bawahan.

Kepemimpinan adalah suatu proses dimana seseorang dapat menjadi pemimpin (leader) melalui aktivitas yang terus-menerus, sehingga dapat mempengaruhi yang dipimpinnya (followers) dalam rangka mencapai tujuan organisasi atau perusahaan. Hubungan antara seorang pemimpin maupun yang dipimpin merupakan suatu proses kepemimpinan karena leader needs followers and followers needs leader dan gaya kepemimpinan yang baik akan berdampak pada kinerja yang tinggi. Kesuksesan perusahaan tergantung pula pada pimpinan dan gaya kepemimpinan yang diterapkan dalam perusahaan. Kinerja manajerial dapat mengalami peningkatan atau penurunan berkaitan dengan gaya kepemimpinan yang diberikan oleh pimpinan. Selain itu, sistem penghargaan juga dapat digunakan sebagai mekanisme untuk memotivasi, mempengaruhi perilaku karyawan dan meningkatkan kinerja manajerial.

Gaya kepemimpinan adalah bagaimana seorang pemimpin melaksanakan fungsi kepemimpinannya dan bagaimana ia dilihat oleh bawahan yang berusaha dipimpinnya atau sekelompok orang yang mungkin sedang mengamati dari luar (Reza, 2010). Gaya kepemimpinan adalah suatu cara yang dimiliki oleh seseorang dalam mempengaruhi sekelompok orang atau bawahan untuk mencapai tujuan yang telah ditetapkan (Candrama, 2011).

Beberapa faktor yang mempengaruhi gaya kepemimpinan (Kadaman, 1999 dalam Budisuharto, 2013) adalah sebagai berikut :

1. Diri pemimpin, dimana kepribadian, pengalaman masa lampau, latar belakang dan harapan pemimpin sangat mempengaruhi efektifitas kepemimpinan disamping mempengaruhi gaya kepemimpinan yang dipilihnya.

2. Ciri atasan, dimana gaya kepemimpinan atasan dari manajer sangat mempengaruhi orientasi kepemimpinan manajer.

3. Ciri bawahan, dimana respon yang diberikan oleh bawahan akan menentukan efektifitas kepemimpinan manajer. Latar belakang pendidikan bawahan sangat menentukan pula cara manajer menentukan gaya kepemimpinannya.

4. Persyaratan tugas, dimana tuntutan tanggung jawab pekerjaan bawahan akan mempengaruhi gaya kepemimpinan manajer.

5. Iklim organisasi dan kebijakan, dimana hal ini akan mempengaruhi harapan dan perilaku anggota kelompok serta gaya kepemimpinan yang dipilih oleh manajer.

6. Perilaku dan harapan rekan, dimana rekan sekerja manajer merupakan kelompok acuan yang penting. Segala pendapat yang diberikan oleh rekan-rekan manajer sangat mempengaruhi efektifitas hasil kerja manajer.

Sistem penghargaan adalah pemberian kompensasi baik financial maupun non financial kepada manajer atau karyawan untuk memotivasi agar kinerja menjadi lebih baik (Wijayanti, 2011). Kompensasi adalah imbalan jasa yang diberikan perusahaan kepada pegawai karena telah memberikan sumbangan tenaga dan pikiran demi kemajuan serta kontinuitas perusahaan dalam rangka mencapai tujuan yang telah ditetapkan baik dalam jangka pendek maupun jangka panjang (Mardiyah et al., 2005). 


\section{Rumusan Masalah}

Adapun rumusan masalah dalam penelitian ini adalah; 1) Bagaimana menganalisis mengenai pengaruh gaya kepemimpinan terhadap kinerja manajerial ?, Bagaimana menganalisis mengenai pengaruh gaya kepemimpinan terhadap kinerja manajerial dengan dimoderasi oleh variabel sistem penghargaan ?.

Agar pembahasan dapat lebih terfokus, maka dilakukan pembatasan masalah pada pengaruh gaya kepemimpinan terhadap kinerja manajerial serta pengaruh gaya kepemimpinan terhadap kinerja manajerial dengan dimoderasi oleh variabel sistem penghargaan. Sehubungan dengan permasalahan yang diajukan

\section{Tujuan dan Manfaat Penelitian}

Penelitian ini bertujuan untuk menganalisis mengenai pengaruh gaya kepemimpinan terhadap kinerja manajerial serta menganalisis mengenai pengaruh gaya kepemimpinan terhadap kinerja manajerial dengan dimoderasi oleh variabel sistem penghargaan. Sedangkan manfaat penelitian ini adalah bahwa secara akademik sebagai syarat beban kerja Dosen pada LLDIKTI Wilayah VIII Bali NTB dan secara teoritis penelitian ini dapat memberikan bukti empiris penerapan teori pendekatan kontingensi dan model kontingensi Fiedler terhadap fenomena di supermarket serta secara praktis dapat memberi tambahan informasi bagi pihak manajemen yang bermanfaat sebagai pertimbangan dalam meningkatkan kinerja manajerial agar lebih produktif, efektif, dan efisien.

\section{METODE PENELITIAN}

\section{Populasi dan Sampel}

Penentuan sampel dalam penelitian ini adalah sampling jenuh yaitu teknik penentuan sampel apabila semua anggota populasi digunakan sebagai sampel (sensus) (Sugiyono, 2005:78). Responden adalah manajer dan staf dengan level terendah supervisor dengan sampel sebanyak 66 responden. Data penelitian dikumpulkan dengan cara menyebarkan 66 kuesioner kepada responden di masing-masing supermarket yang menjadi obyek penelitian. Kuesioner yang kembali adalah sebanyak 66 kuesioner. Dengan demikian jumlah kuesioner yang kembali itulah merupakan sampel dalam penelitian ini. Berkaitan dengan penjelasan di atas, maka tingkat pengembalian kuesioner (response rate) dalam penelitian ini adalah sebesar $100 \%$.

\section{Definisi Operasional Variabel \\ Kinerja Manajerial}

Kinerja manajerial dalam penelitian ini adalah kinerja manajer dalam kegiatan-kegiatan manajerial. Kinerja manajerial diukur dengan delapan indikator yaitu perencanaan, investigasi, pengkoordinasian, evaluasi, pengawasan, pengaturan staf, negosiasi, dan perwakilan. Indikator kinerja manajerial diukur dengan menggunakan indikator self rating (Sumarno, 2005). Pengukuran indikator dilakukan dengan menggunakan skala interval dengan rentang 1 sampai 9, dimana rentang dari 1 sampai dengan 3 menunjukkan kinerja di bawah rata-rata, 4 sampai dengan 6 menunjukkan kinerja rata-rata, dan 7 sampai dengan 9 menunjukkan kinerja di atas rata-rata.

\section{Gaya kepemimpinan}

Gaya kepemimpinan merupakan berbagai pola tingkah laku yang disukai oleh pemimpin dalam proses mengarahkan dan mempengaruhi bawahan. Variabel gaya kepemimpinan dengan dua indikator (kepemimpinan yang berorientasi pada tugas dan hubungan) diukur menggunakan instrumen yang dikenal dengan LPC (Least Preferred Coworker) yang dikembangkan oleh Fiedler (1967). Skala ini merupakan pasangan kata yang berlawanan, yaitu meliputi 16 pasangan kata dengan skor 1 sampai 8. Jika jumlah skor LPC 57 atau lebih, berarti LPC tinggi atau berorientasi pada hubungan dan jika skor LPC kurang dari 57, berarti LPC rendah atau berorientasi pada tugas.

\section{Sistem Penghargaan}

Sistem penghargaan adalah segala bentuk pengembalian baik finansial maupun non finansial yang diterima karyawan karena jasa yang disumbangkan ke perusahaan (Mintje, 2013). Sistem penghargaan diukur dengan indikator financial (berupa gaji, upah, tunjangan) dan non financial (berupa pengakuan, promosi, dukungan). Indikator diukur dengan menggunakan skala interval (nilai $1=$ sangat tidak setuju, nilai $2=$ tidak setuju, nilai $3=$ cukup setuju, nilai $4=$ setuju, nilai $5=$ sangat setuju) (Jogiyanto, 2007:67). 


\section{Uji Hipotesis}

Penelitian ini menggunakan analisis regresi sederhana untuk melihat pengaruh variabel independen terhadap variabel dependen yaitu pengaruh gaya kepemimpinan terhadap kinerja manajerial. Sementara itu, untuk menguji pengaruh variabel pemoderasian yaitu sistem penghargaan terhadap hubungan antara gaya kepemimpinan terhadap kinerja manajerial digunakan uji interaksi/Moderated Regression Analysis (MRA).

Persamaan yang digunakan untuk menentukan pengaruh variabel gaya kepemimpinan terhadap kinerja manajerial adalah, sebagai berikut :
$\mathrm{Y}=\mathrm{a}+\mathrm{b}_{1} \mathrm{X}_{1}+\mathrm{e}$
(Wijaya, 2011:92)

Persamaan statistika dalam uji interaksi yang digunakan untuk menentukan variabel pemoderasian dalam hubungan gaya kepemimpinan terhadap kinerja manajerial adalah, sebagai berikut :

$\mathrm{Y}=\mathrm{a}+\mathrm{b}_{1} \mathrm{X}_{1}+\mathrm{b}_{2} \mathrm{X}_{2}+\mathrm{b}_{3} \mathrm{X}_{1} \mathrm{X}_{2}+\mathrm{e}$ (Ghozali, 2006:164)

Dimana :

$\mathrm{Y} \quad=$ Kinerja manajerial

$\mathrm{X}_{1} \quad$ = Gaya kepemimpinan

$\mathrm{X}_{2} \quad=$ Sistem penghargaan sebagai variabel moderasi

$\mathrm{X}_{1} \mathrm{X}_{2}=$ Interaksi TQM dengan sistem penghargaan

a $\quad=$ Konstanta

e $\quad=$ Error

\section{HASIL DAN PEMBAHASAN}

\section{Pengujian Hipotesis Pertama $\left(\mathbf{H}_{1}\right)$}

Hasil analisis untuk menentukan pengaruh variabel gaya kepemimpinan terhadap kinerja manajerial, dapat dilihat pada Tabel 1 dan 2.

Tabel 1. Hasil Analisis Pengaruh Gaya Kepemimpinan $\left(\mathbf{X}_{1}\right)$ terhadap Kinerja Manajerial $(\mathbf{Y})$ Model Summary ${ }^{\mathrm{b}}$

\begin{tabular}{|c|c|c|c|c|}
\hline Model & R & R Square & Adjusted R Square & Std. Error of the estimate \\
\hline 1 & $.850^{\mathrm{a}}$ & .723 & .718 & .173929 \\
\hline
\end{tabular}

Sumber : Data Primer Diolah

Tabel 2. Coefficients ${ }^{\mathrm{a}}$

\begin{tabular}{|cc|c|c|c|c|c|}
\hline Model & \multicolumn{3}{|c|}{ Unstandardized Coefficients } & $\begin{array}{c}\text { Standardized } \\
\text { Coefficients }\end{array}$ & & \\
\hline & & B & Std. Error & Beta & t & Sig. \\
\hline 8 & (Constant) & 2.085 & .096 & & 21.734 & .000 \\
GK & -.016 & .001 & -.850 & -12.915 & .000 \\
\hline
\end{tabular}

Sumber : Data Primer Diolah

Hasil analisis regresi sederhana untuk menguji pengaruh gaya kepemimpinan terhadap kinerja manajerial dalam Tabel 1. menunjukkan bahwa nilai Adjusted $R$ Square $\left(\mathrm{R}^{2}\right)$ sebesar 0,718 yang berarti variabilitas/perubahan kinerja manajerial $(\mathrm{Y})$ dapat dijelaskan oleh gaya kepemimpinan $\left(\mathrm{X}_{1}\right)$ sebesar 71,8 persen dan sisanya 28,2 persen dijelaskan oleh variabel lain yang tidak dimasukkan dalam model penelitian.

Nilai $t_{\text {hitung }}$ pada variabel gaya kepemimpinan $\left(\mathrm{X}_{1}\right)$ sebesar $-12,915$ dengan tingkat signifikan sebesar $0,000(<0,05)$. Hal ini berarti gaya kepemimpinan $\left(X_{1}\right)$ secara parsial berpengaruh negatif dan signifikan terhadap kinerja manajerial (Y). Dengan demikian jika gaya kepemimpinan ditingkatkan maka akan menurunkan kinerja manajerial. Artinya gaya kepemimpinan yang diterapkan dalam supermarket mempunyai peran penting dalam meningkatkan atau menurunkan kinerja manajerial.

Hasil penelitian ini mendukung teori pendekatan kontingensi dimana dalam teori tersebut bahwa untuk menjadi pemimpin efektif harus ada kecocokan antara perilaku pemimpin dan gaya pemimpin pada kondisi dan situasi dalam organisasi. Peranan pemimpin dalam supermarket sangat diperlukan untuk menciptakan motivasi tinggi, sehingga timbul semangat kerja yang dapat meningkatkan kinerja manajerial dengan memperhatikan situasi yang terdapat dalam organisasi. Dengan demikian gaya kepemimpinan yang diterapkan harus fleksibel, disesuaikan dengan keadaan dan kebutuhan bawahan.

\section{Pengujian Hipotesis Kedua $\left(\mathrm{H}_{2}\right)$}

Hasil analisis untuk menentukan pengaruh gaya kepemimpinan terhadap kinerja manajerial dengan dimoderasi oleh sistem penghargaan dapat dilihat pada Tabel 3, 4 dan 5. 
Tabel 3. Hasil Analisis Pengaruh Gaya Kepemimpinan $\left(X_{1}\right)$ terhadap Kinerja Manajerial $(Y)$ dengan Dimoderasi oleh Sistem Penghargaan $\left(\mathbf{X}_{2}\right)$

Model Summary

\begin{tabular}{|c|c|c|c|c|}
\hline Model & R & R Square & Adjusted R Square & Std. Error of the estimate \\
\hline 1 & $.936^{\mathrm{a}}$ & .877 & .871 & .117929 \\
\hline & & & & \\
\hline
\end{tabular}

Sumber : Data Primer Diolah

Tabel 4. ANOVA

\begin{tabular}{|ll|l|l|l|l|c|}
\hline & Model & Sum of Squares & \multicolumn{1}{|c|}{ Df } & Mean Square & F & Sig. \\
\hline 1 & Regression & 6.120 & 3 & 2.040 & 146.686 & $.000^{\mathrm{a}}$ \\
& Residual & .862 & 62 & .014 & & \\
\hline & Total & 6.982 & 65 & & & \\
\hline
\end{tabular}

Sumber : Data Primer Diolah

Tabel 5. Coefficients ${ }^{\mathrm{a}}$

\begin{tabular}{|c|c|c|c|c|c|}
\hline \multirow[t]{2}{*}{ Model } & \multicolumn{2}{|c|}{ Unstandardized Coefficients } & \multirow{2}{*}{$\begin{array}{c}\text { Standardized } \\
\text { Coefficients } \\
\text { Beta }\end{array}$} & \multirow[b]{2}{*}{$\mathbf{t}$} & \multirow[b]{2}{*}{ Sig. } \\
\hline & B & Std. Error & & & \\
\hline 1 (Constant) & .768 & .214 & & 3.593 & .001 \\
\hline GK & .000 & .002 & -.028 & -.273 & .786 \\
\hline SP & 1.735 & 198 & 986 & 8.779 & .000 \\
\hline Moderat 2 & -.020 & .005 & -.221 & -4.145 & .000 \\
\hline
\end{tabular}

Sumber : Data Primer Diolah

Tabel 3. menunjukkan nilai adjusted $R$ Square $\left(\mathrm{R}^{2}\right)$ sebesar 0,871 , hal ini berarti 87,1 persen variasi/perubahan kinerja manajerial dapat dijelaskan oleh variabel gaya kepemimpinan, sistem penghargaan, interaksi gaya kepemimpinan dan sistem penghargaan, sedangkan sisanya 12,9 persen dijelaskan oleh variabel lain yang tidak dimasukkan dalam model penelitian.

Uji Anova atau $F$ test pada tabel 4. menghasilkan nilai $F_{\text {hitung }}>F_{\text {tabel }}(146,686>2,76)$ dengan tingkat signifikansi 0,000 . Karena $\mathrm{F}_{\text {hitung }}>\mathrm{F}_{\text {tabel }}$ dan probabilitas signifikansi jauh lebih kecil dari 0,05 , maka model regresi dapat digunakan untuk memprediksi kinerja manajerial. Artinya gaya kepemimpinan, sistem penghargaan, interaksi gaya kepemimpinan dengan sistem penghargaan secara bersama-sama berpengaruh terhadap kinerja manajerial.

Dari Tabel 5. dapat dijelaskan bahwa variabel sistem penghargaan, interaksi gaya kepemimpinan dan sistem penghargaan berpengaruh secara signifikan terhadap kinerja manajerial. Variabel sistem penghargaan memberikan nilai koefisien parameter 1,735 dengan tingkat signifikansi 0,000 dan variabel moderat2 memberikan nilai koefisien parameter sebesar $-0,020$ dengan tingkat signifikansi sebesar $0,000(<0,05)$. Variabel moderat2 yang merupakan interaksi gaya kepemimpinan dan sistem penghargaan ternyata signifikan, sehingga dapat disimpulkan bahwa variabel sistem penghargaan mempengaruhi hubungan (memoderasi) gaya kepemimpinan terhadap kinerja manajerial. Artinya dengan adanya sistem penghargaan akan dapat memperlemah pengaruh gaya kepemimpinan terhadap kinerja manajerial.

Dengan demikian penerapan gaya kepemimpinan yang tinggi disertai dengan pemberian sistem penghargaan yang tinggi belum tentu dapat meningkatkan kinerja manajerial, karena peningkatan gaya kepemimpinan yang tidak disesuaikan dengan situasi dan kondisi yang dihadapi manajer dalam supermarket akan menurunkan kinerja manajerial meskipun sistem penghargaan yang diberikan pimpinan cenderung tinggi.

\section{PENUTUP}

\section{Simpulan}

Berdasarkan masalah, pembahasan, dan hasil analisis data mengenai pengaruh gaya kepemimpinan terhadap kinerja manajerial dengan pemoderasi variabel sistem penghargaan pada supermarket di Mataram, maka dapat diambil kesimpulan sebagai berikut :

1. Gaya kepemimpinan berpengaruh signifikan terhadap kinerja manajerial tetapi arah hubungannya negatif.

2. Sistem penghargaan mempengaruhi hubungan gaya kepemimpinan terhadap kinerja manajerial tetapi arah hubungannya negatif. 


\section{Saran}

Dengan memperhatikan kesimpulan yang telah dikemukakan, maka dapat disajikan saran yang diharapkan dapat memberikan manfaat dan dapat digunakan sebagai bahan pertimbangan untuk penelitian selanjutnya di masa yang akan datang. Dari hasil analisa dan kesimpulan yang telah diperoleh di atas, maka peneliti menyarankan sebagai berikut :

1. Penelitian ini menggunakan responden yang hanya terbatas pada supermarket di wilayah Kota Mataram maka disarankan untuk peneliti selanjutnya sebaiknya memperluas sampel penelitian

2. Disarankan untuk peneliti selanjutnya dapat menambahkan variabel-variabel lain terkait dengan pengaruhnya terhadap kinerja manajerial, misalnya six sigma, balance scorecard, dan variabel lainnya.

\section{DAFTAR PUSTAKA}

Budisuharto. (2013). Pengaruh Gaya Kepemimpinan Terhadap Kinerja Karyawan Pada Hotel Amaris Panakukang Makassar (Skripsi). Fakultas Ekonomi dan Bisnis. Universitas Hasanuddin Makassar.

Candrama, Kadek Teja. (2011). Pengaruh Total Quality Management (TQM), Gaya Kepemimpinan, Kedisiplinan Kerja dan Fungsi Mentoring Terhadap Kinerja Karyawan PT. Pos Indonesia, Kantor Pos Yogyakarta (Skripsi). Fakultas Ekonomi Universitas Pembangunan Nasional "Veteran", Yogyakarta.

Ghozali, Imam. (2006). Aplikasi Analisis Multivariate dengan Program SPSS. Badan Penerbit Universitas Diponegoro Semarang.

Jogiyanto. (2007). Metodologi Penelitian Bisnis, BPFE. Yogyakarta.

Mardiyah, Aida Ainul \& Listianingsih. (2005). Pengaruh Sistem Pengukuran Kinerja, Sistem Reward dan Profit Center Terhadap Hubungan antara Total Quality Management dengan Kinerja Manajerial, Simposium Nasional Akuntansi VII.

Mintje, Nastiti. (2013). Pengaruh TQM, Sistem Penghargaan dan Sistem Pengukuran Kinerja terhadap Kinerja Manajerial pada PT. Air Manado, Jurnal EMBA, 2013, Vol. 1 No. 03.

Nurfitriana, Ina, Grahita Chandrarin \& Hanif Ismail. (2005). Teknologi Informasi, Sistem Pengukuran Kinerja dan Penghargaan Sebagai Pemoderasi Hubungan antara TQM dengan Kinerja Manajerial, Akuntabilitas, 2005, Vol. 5 No. 1:17-34.

Reza, Regina Aditya. (2010). Pengaruh Gaya Kepemimpinan, Motivasi dan Disiplin Kerja Terhadap Kinerja Karyawan PT. Sinar Santosa Perkasa Banjarnegara (Skripsi), Fakultas Ekonomi Universitas Diponegoro Semarang.

Robbins, Stephen P. \& Timothy A. Judge. (2009). Perilaku Organisasi. Jakarta: Salemba Empat

Safaria, Triantoro. (2004). Kepemimpinan. Yogyakarta: Graha Ilmu

Sugiyono. (2005). Metode Penelitian Bisnis. Bandung: CV. Alfabeta.

Sumarno, J. (2005). Pengaruh Komitmen Organisasi dan Gaya Kepemimpinan Terhadap Hubungan antara Partisipasi Anggaran dan Kinerja Manajerial (Studi Empiris Pada Kantor Cabang Perbankan Indonesia di Jakarta), Simposium Nasional Akuntansi VIII.

Wijaya, Tony. (2011). Cepat Menguasai SPSS 19 untuk Olah dan Interpretasi. Yogyakarta: Cahaya Atma

Wijayanti, Elly. (2011). Pengaruh Sistem Pengukuran Kinerja dan Sistem Penghargaan Terhadap Keefektifan Penerapan Teknik Total Quality Management (TQM) (Skripsi), Fakultas Ekonomi Universitas Pembangunan Nasional "Veteran". Jakarta. 